\title{
Problemas Ambientais no Município de Meruoca, Ceará, Brasil
}

\author{
Environmental Problems in Meruoca, Ceará, Brazil \\ MENDES $^{1}$, M. V. R.; DINIZ², S. F.; FALCÃO ${ }^{3}$, C. L. C. \\ marcos.venicios10@hotmail.com
}

\begin{abstract}
Resumo
O nosso planeta é afetado por distintos problemas ambientais, sendo sua maioria praticados pela ação humana que acabam atingindo a fauna, flora, água, ar e solo. Perante essa situação, percebe-se que qualquer atividade executada pelo homem no meio ambiente, ocasionará em problemas ambientais, sejam de ordem positiva ou negativa, resultando muitas das vezes em degradação. Relacionado a isso temos como exemplo a serra da Meruoca, nosso objeto de estudo que está localizada na parcela noroeste cearense. A pesquisa foi realizada a partir da TGS propositada por Bertalanffy (2008) que apresenta a interação dos elementos do meio físico, conforme a dinâmica de seus processos naturais e antrópicos, que contou ainda com atividades de campo para coletas de dados cartográficos, e coletas de solos para fins de análises físicas, além de registros fotográfico. Os resultados mostram que os problemas no Município são diversos, como a poluição dos recursos hídricos, assoreamento, especulação imobiliária e principalmente o solo que vem sofrendo com processo de erosão. Resta no dizer que muitas melhorias devem ser executadas por parte do poder público, promovendo medidas mitigadoras a fim de amenizar eventos adversos tendo em vista que o Município faz parte da Área de Preservação Ambiental-APA.
\end{abstract}

Palavras-chave: Maciço residual; atividades agrícolas; solos.

\begin{abstract}
Our planet is affected by different environmental problems, mostly practiced by human action that end up affecting the fauna, flora, water, air and soil. Given this situation, it is clear that any activity performed by man in the environment will cause environmental problems, whether positive or negative, often resulting in degradation. Related to this we have as an example the Serra da Meruoca, our object of study that is located in the northwestern part of Ceará. The research was conducted from the TGS proposed by Bertalanffy (2008) which presents the interaction of the elements of the physical environment, according to the dynamics of their natural and anthropic processes, which also had field activities for cartographic data collection that supported the making of cartographic material, as well as photographic records. The results show that the problems in the municipality are diverse, such as pollution of water resources, siltation, real estate speculation and especially the soil that has been suffering from erosion. It remains to be said that many improvements must be implemented by the government, promoting mitigating measures in order to mitigate adverse events considering that the Municipality is part of the Environmental Preservation Area-APA.
\end{abstract}

Keywords: Residual assif; agricultural activities; soils.

\section{INTRODUÇÃO}

A ciência geográfica que faz a investigação da relação entre sociedade e natureza, tem como objeto principal de estudo o espaço geográfico que corresponde ao palco das relações humanas. A partir dessa relação existente entre sociedade e natureza, surge os problemas ambientais, que ocorrem desde a época da colonização. Dessa forma nosso planeta é afetado

\footnotetext{
${ }^{I}$ Marcos Venicios Ribeiro Mendes, Programa de Mestrado Acadêmico em Geografia, Universidade Estadual Vale do Acaraú, Sobral-CE, Brasil.

${ }^{2}$ Simone Ferreira Diniz, Centro de Ciências Humanas, Universidade Estadual Vale do Acaraú, Sobral-CE, Brasil.

${ }^{3}$ Cleire Lima da Costa Falcão, Departamento de Geografia, Universidade Estadual do Ceará, Fortaleza-CE, Brasil.
} 
por diversos problemas e questões ambientais, sendo a maioria ocasionados pela ação humana, afetando diretamente ao meio ambiente, tais como (fauna, flora, solos, águas, ar).

Partindo desse pensamento, tem-se os principais problemas que afetam o meio ambiente, como bem destaca o Ministério do Meio Ambiente- MMA (2016) quando vem afirmar que o problema que mais causa danos ao meio ambiente é o desmatamento, sendo cerca de $67 \%$ do território atingido. Os demais problemas estão voltados à poluição do ar (36\%) desperdício de águas (10\%) poluição dos recursos hídricos (47\%) elevação na geração de resíduos sólidos (28\%), camada de ozônio (9\%) e ainda as alterações climáticas (6\%), entre outros problemas de menor escala.

Aliado a essa informação, Dias (2008) aponta que na segunda metade do século XX, com o fortalecimento do crescimento econômico mundial, os problemas ambientais se intensificaram e começaram a surgir com maior visibilidade nos diversos setores da população, surgindo os movimentos ecologistas a fim de priorizar atenção especial ao que a ação humana poderia causar ao meio ambiente.

Assim, temos as áreas de maciços residuais úmidos, em meio ao semiárido Nordestino, onde a ação humana é permanente, motivo esse por apresentar um cenário físiconatural diferenciado das demais unidades geomorfológicas do semiárido, prevalecendo nesses ambientes a prática da agricultura. Tal concepção pode ser atestada em lições de Costa Falcão (2002) quando vem nos revelar que "essas áreas são privilegiadas do semiárido em função da importância da quase totalidade da sua produção agrícola, e como deveriam ser as primeiras a receberem maiores cuidados, no sentido de conservar e recuperar os seus solos".

Em consequência disso, iniciam-se os primeiros impactos ambientais em escalas consideráveis, como manuseio do solo para cultivos, queima e desmatamento, utilização de matéria-prima para a construção de edificações. Os estudos de impactos ambientais constituem uma visão do comportamento das condições naturais, como também das ações humanas que são nelas exercidas, visto que modificações significantes em qualquer uma de suas unidades correm o risco de ocasionar transformações/ impactos.

Conforme Christofoletti (1995), o impacto ambiental possui componentes espaciais e temporais, podendo ser descrito através das alterações nos parâmetros do meio ambiente, naturais ou sociais, durante certo período em uma determinada área. Ao longo dos anos a problemática ambiental ou degradação do meio ambiente, pode ser classificada como um tipo de impacto que diminui as chances de um ecossistema sustentável. Essas alterações podem ocorrer em razão do uso inadequado do solo, com práticas não sustentáveis, trazidas de área 
de climas diferentes do local onde são implantadas, deixando impactos muitas vezes irreversíveis.

Acredita-se ainda, que as principais práticas que contribuem para a degradação ambiental são as queimadas, os desmatamentos e os processos erosivos. Nesse enfoque, as preocupações relacionadas a esse tema têm-se tornado constantes, tal intervenção provoca uma série de danos à natureza, alterando os espaços naturais e construindo novas paisagens. Em contrapartida, este desenvolvimento trouxe à tona preocupações com a degradação imposta ao meio ambiente, sendo o ponto de partida para as discussões referentes à preservação ambiental e a minimização destes impactos.

Insere-se na Lei $\mathrm{n}^{\circ}$ 6.938, de 31 de agosto de 1981, que institui a Política Nacional de Meio Ambiente, artigo $3^{\circ}$, inciso II, o seguinte conceito alusivo ao termo degradação ambiental: "degradação da qualidade ambiental, a alteração adversa das características do meio ambiente". Ainda que bastante simplificado, o conceito expressa que a degradação ambiental possui uma conotação negativa, desta forma considera-se a necessidade de se estabelecerem as definições, as responsabilidades, os critérios básicos e as diretrizes gerais para uso e implementação da Avaliação de Impacto Ambiental como um dos instrumentos da Política Nacional do Meio Ambiente.

A resolução do conselho nacional do meio ambiente, CONAMA 001 de 23/01/1986 Art. $1^{\circ}$ considera-se impacto ambiental qualquer alteração das propriedades físicas, químicas e biológicas do meio ambiente, causada por qualquer forma de matéria ou energia resultante das atividades humanas que, direta ou indiretamente, afetam:

I - A saúde, a segurança e o bem-estar da população;

II - As atividades sociais e econômicas;

III - A biota;

IV - As condições estéticas e sanitárias do meio ambiente;

$\mathrm{V}$ - A qualidade dos recursos ambientais

Todavia, o que mais demarca as mudanças nas paisagens é a erosão, processo que provoca a remoção da vegetação do solo fazendo com que a superfície perca sua consistência, possibilitando que a água penetre no solo de forma acentuada, causando, muitas vezes, o processo de lixiviação. Essa água ao se acumular pode causar a instabilidade do solo acelerando os processos erosivos.

A atividade de mineração ou retirada de grandes quantidades de terra é um dos indicadores da erosão de grandes áreas. Principalmente onde os projetos não seguem o EIARIMA (Estudo de Impacto Ambiental e Relatório de Impacto Ambiental). Temos como 
exemplo a serra da Meruoca, uma área úmida, que atualmente vem sofrendo modificações pela interferência do homem nesse ambiente, transformando e alterando as paisagens que compõem esta região.

Porém, a serra da Meruoca vem sofrendo com processos ambientais que envolvem tanto a vegetação quanto os solos, estes ocorrem especialmente devido ao desmatamento e manejo inapropriado dos solos. A exploração dos recursos naturais é resultante de vários tipos de atividades, destacando-se as práticas agrícolas. A respeito disso Costa Falcão (2008) chama a atenção para o fato de que, as práticas agrícolas exercidas na área são realizadas com técnicas inadequadas, prejudicando os recursos pedológicos deste ambiente.

Em relação aos problemas resultantes das práticas agrícolas, Falcão Sobrinho e Costa Falcão (2001, p.36), em seus ensinamentos relatam que "na serra da Meruoca devido à falta de informação os agricultores utilizam a prática da queimada como medida mais rápida para eliminação de espécies vegetais como maneira de limpeza da área".

Tal situação acontece nas áreas onde os pequenos agricultores exercem suas atividades, sendo estes desprovidos das tecnologias, predominando as práticas tradicionais, fortalecendo o aceleramento dos processos erosivos.

\section{LOCALIZAÇÃO E CARACTERIZAÇÃO DA ÁREA DE ESTUDO}

O Munícipio de Meruoca (serra da Meruoca) está situado na Região Noroeste Cearense. Sua distância é aproximadamente 260 quilômetros da capital Fortaleza, tendo como via de acesso a BR-222. No que se refere à sua localização cartográfica está posicionada nas coordenadas geográficas 3³2’ 30” Latitude (S) e Longitude (W) 40²7’ 18”. (IPECE, 2017)

Os Municípios que estão ao seu limite são: Ao Norte, Massapê, ao Sul, Sobral, ao Leste, Massapê e ao Oeste, Alcântara (IPECE, 2017). Ainda em relação à área, expressa uma forma retangular com comprimento de 20 a $25 \mathrm{~km}$ (SOUZA, 1988). (Figura 01 e 02). 

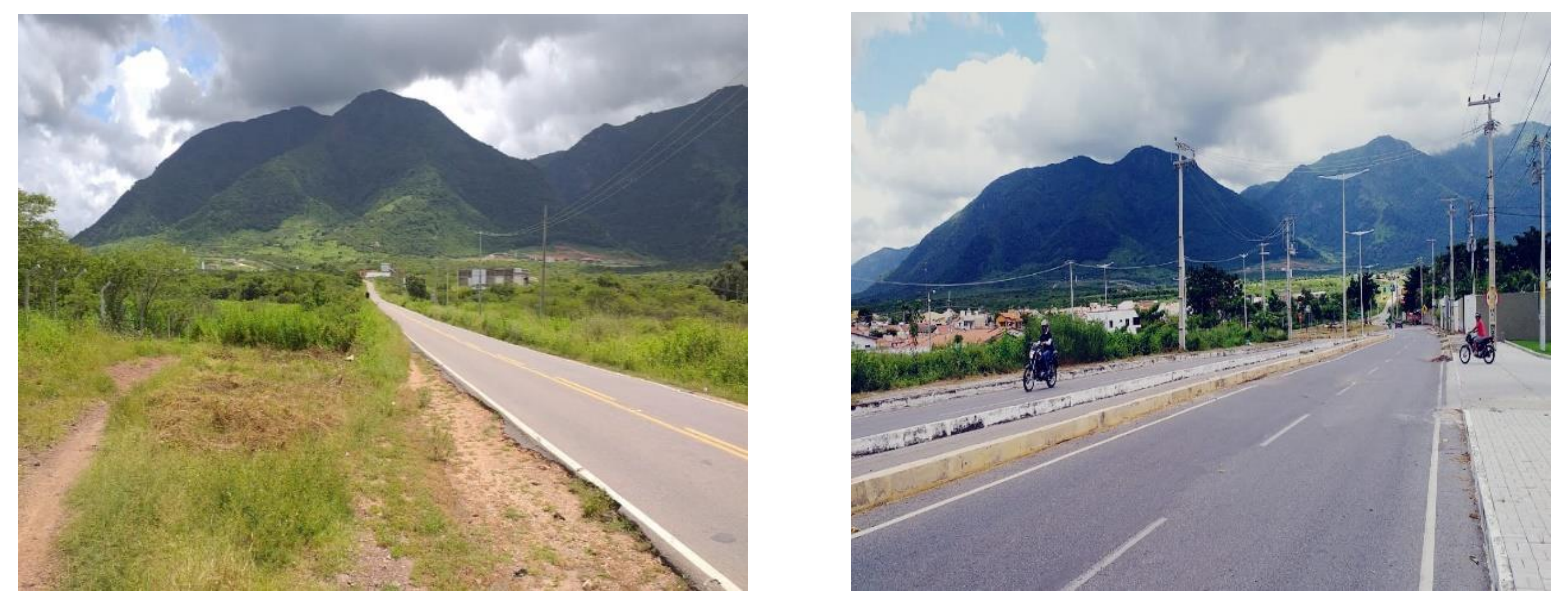

Figura 01e 02: Imagens da serra da Meruoca. Fonte: Autores (2019).

Encravada no ambiente semiárido do Nordeste Brasileiro, ocupando uma área de aproximadamente $788.064 \mathrm{~km}^{2}$ que é os equivalentes a $48 \%$ do Nordeste e a 9,3\% do Brasil, onde tem-se com a relativa heterogeneidade natural da região semiárida, por meio da subcompartimentação das unidades geossistêmicas. (SOUZA; OLIVEIRA, 2006).

Soma-se ainda aos argumentos de Souza e Oliveira (2006) ao relatarem que no contexto geoecológico do ambiente semiárido, inteiramente sobreposto ao aspecto fitogeográfico das caatingas, tem-se ambientes de exceção que denotam as áreas dos enclaves úmidos, matas úmidas, caracterizando a área de estudo da pesquisa. Em seguida (Figura 03), representa a localização da área de estudo.

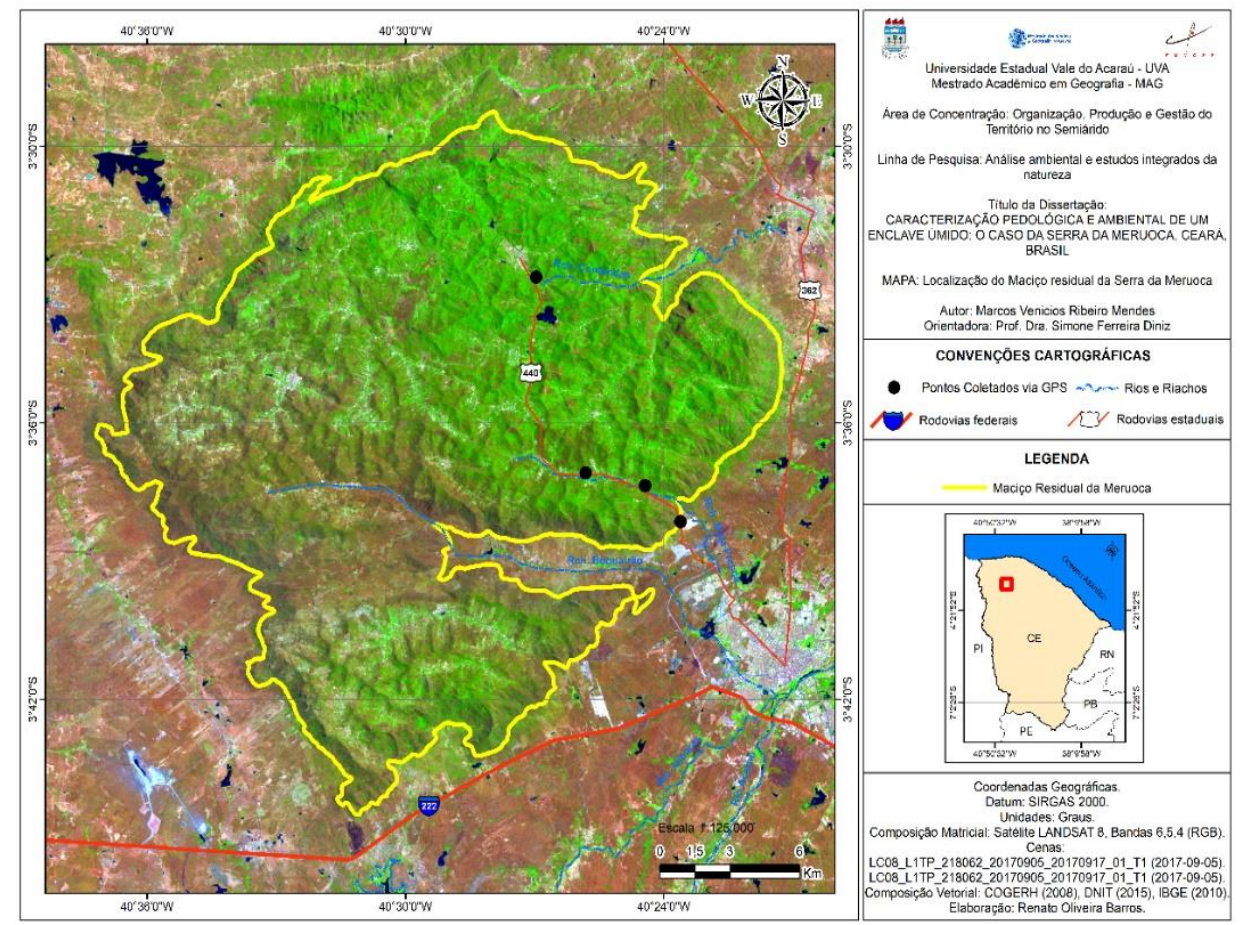

Figura 03: Localização da área de estudo. Fonte: BARROS, MENDES (2019). 
Atualmente a serra da Meruoca pertence a uma área de preservação ambiental, que foi criada conforme a Lei de Federal $\mathrm{n}^{\circ}$ 11. 891, sancionada em 24 de dezembro de 2008, abrangendo uma área de 29.361,27 hectares. A área de preservação ambiental-APA da serra da Meruoca apresenta uma delimitação, distribuída em Setor A e Setor B.

Para o setor A temos as vertentes nordeste, leste e sudeste, a partir da cota de $200 \mathrm{~m}$ (duzentos metros) de altitude, nos Municípios de Meruoca e Massapê. Já para o setor B está toda a área compreendida acima da cota de 600m (seiscentos metros) de altitude, nos Municípios de Meruoca, Massapê, Alcântara e Sobral.

Para fins de análise integrada da serra da Meruoca propõe-se uma caracterização dos componentes naturais. Portanto, por meio de levantamentos bibliográfico foi executada uma integração do quadro natural, composto por: geologia geomorfologia, pedologia, vegetação, clima, hidrogeografia, que proporciona o entendimento de uma determina área.

Assim, a estrutura geológica é composta basicamente por rochas do embasamento cristalino. É intrusivo em rochas do Complexo Granja e nos grupos Martinópolis e Ubajara no flanco norte, e limita-se com a Bacia do Jaibaras, a leste, por meio da Falha Café-Ipueiras (CPRM, 2014).

A partir da classificação de Ab’ Sáber (1999) quando apresenta o nordeste seco,assim como os seus dominios morfoclimáticos (2003) a serra da Meruoca, configura-se como um Brejo de altitude, termo esse aplicado em localidades com consições de umidade que proporciona a formação e existência original de florestas, em fortes constrates com os sertões secos.

De modo geral, as classes de solos predominantes na área em apreço são: Argissolos Vermelho-Amarelos, Neossolos. Dessa forma Diniz (2010) expõe comentários dizendo que esse tipo de solo são solos minerais não hidromórficos, com horizonte A ou E contíguos ao B textural não plíntico, argila de alta ou baixa atividade e teores de ferro inferiores a $11 \%$.

Enquanto os Neossolos conforme Diniz (2010) as suas características principais estão voltadas a restrição agrícola, além de serem rasos, pouco evoluídos constituídos por material mineral, que admitem a presença de horizonte $\mathrm{B}$.

Possui uma vegetação em altas altitudes do tipo floresta subperenifólia tropical plúvionebular, ou mata úmida serrana, e em baixas altitudes do tipo floresta subcaducifólia espinhosa, ou mata seca. Ab’Sáber (2003) expressa que os enclaves representam fatos isolados apresentando características físico-ecológicas distintas, configurando verdadeiras paisagens de exceção. 
O clima enquadra-se no tipo climático Amw', e com isso Àb Sáber (1974) reforça ao pronunciar que essa região é de clima azonal em ligação às faixas tropicais e subtropicais, fazendo com que as médias de precipitação nesse ambiente permanecem quase sempre com $1.000 \mathrm{~mm}$

Em se tratando dos recursos hídricos, a serra da Meruoca constitui um relevante divisor de água dos rios Acaraú e Coreaú. As suas principais drenagens, tem como destaque o riacho Contendas, Boqueirão. Assim sendo, Souza e Oliveira (2006), em suas palavras mencionam que a serra da Meruoca é um dispersor de drenagem oriundos da vertente norte e leste demanda do rio Acaraú. Os riachos da vertente oeste confluem com o rio Coreaú.

Relacionado às águas subterrâneas, a estrutura geológica cristalina expõe um baixo potencial hidrogeológico. Conforme a CPRM (1998) a área apresenta domínio hidrogeológico predominante em rochas cristalinas (aquíferos fissurais) e depósitos aluvionares, (aquíferos granulares). Dentre os açudes principais, destacam-se os açudes Pedra, Quebra e Jenipapo.

\section{METODOLOGIA}

No referido artigo empregamos a metodologia tendo como base a princípio a revisão bibliográfica de alguns autores que estudam sobre a temática em questão, envolvendo as características do meio físico da área, tais como: relevo, solo, vegetação, clima, e recursos hídricos. Diante disso, adotamos a teoria geral dos sistemas-TGS proposta por Bertalanffy (2008) como suporte para o entendimento do meio físico da área conforme a dinâmica de seus processos naturais e antropogênicos, enfocando principalmente os solos recurso natural que vem sendo alvo explorado no Município.

Foram realizados trabalhos de campo para o reconhecimento da área, com observações e descrições quanto aos aspectos físicos que compõem o ecossistema, identificando as principais unidades ambientais e caracterização das principais modificações, com os devidos registros fotográficos e coordenadas para a confecção do mapa, bem como coletas de solos para fins de análises físicas, e pôr fim a congregação dos dados para a produção do trabalho aqui apresentado.

Em relação às coletas dos solos, foram coletadas duas amostras. Salientamos que o material coletado foi retirado da camada arável aproximadamente $(60 \mathrm{~cm})$ de um Argissolo Vermelho-Amarelo e de um Neossolo. Para tanto, a quantidade do material coletado, foi aproximadamente $1 \mathrm{~kg}$ de cada solo. 
Em seguida, as amostras foram levadas ao Laboratório de Solos do Instituto Federal de Educação, Ciência e Tecnologia do Ceará (IFCE) Campus Sobral. Vale destacar que as análises físicas seguiram orientações da $3^{\mathrm{a}}$ Edição e Revista Ampliada do Manual de Método de Análise de Solo (EMBRAPA, 2017).

As áreas de coletas foram classificadas da seguinte forma:

Coleta da Área I: (Argissolos Vermelho-Amarelos)

De coordenadas: $03^{\circ} 32^{`} 811^{\prime \prime}$ "Latitude (S); Longitude (W) 040 $27^{`}$ 058”, com altitude de $697 \mathrm{~m}$, estando localizado em uma área com vegetação. Localizado próximo a um colégio da rede municipal de Meruoca.

Coleta da Área II: (Neossolos)

De coordenadas: $03^{\circ} 36^{\prime} 4.674$ 'Latitude (S); Longitude (W) 40²7' 31.848”, com altitude de 984 m, está localizado próximo a uma torre da empresa OI.

No que diz respeito a coleta e preparo das amostras, estas são de suma importância para posteriores análises, seja de qualquer espécie, física, química, mineralógica, entre outras. Partindo dessa premissa, Fontana et al (2017, p.22) observam que "o preparo das amostras é a operação a ser realizada juntamente com o registro antes da entrada para as análises laboratoriais". Prosseguindo com a discussão, o preparo tem o propósito de adaptar as amostras aos procedimentos analíticos no laboratório e permitir sua homogeneização (FONTANA et al, 2017).

Análises Físicas: As amostras após passagem por uma secagem em estufa a $40^{\circ} \mathrm{C}$, no período de 24horas para redução da umidade de extração, foram então beneficiadas em moinho e uso de peneiras para separação da fração grosseira.

Desta feita as amostras foram armazenadas em sacos plásticos, com as suas devidas etiquetas de identificação. Logo após a secagem, foram destorroadas e separadas em frações por peneiramento nas peneiras de malha de $20 \mathrm{~mm}$ e de $2 \mathrm{~mm}$, que por sua vez obtido o material denominado de "terra fina seca ao ar" (TFSA).

Para tanto foi adotado o método da pipeta, tendo como base na lei de Stokes, usando como dispersante o $\mathrm{NaOH} 1 \mathrm{~mol}^{1}$. No que diz respeito à fração areia, esta foi separada por peneiramento, enquanto a argila separada por sedimentação, sendo calculada a fração silte por diferença. A avaliação da argila dispersa em água (ADA) foi procedida por separação da fração argila por sedimentação do silte. A medição da fração argilosa foi realizada por pesagem e secagem da amostra em estufa (método padrão) ou da densidade de suspensão, utilizando água deionizada e fenolftaleína pelo método da pipeta. Enquanto a densidade de partícula foi titulada com álcool (EMBRAPA, 2017). 
A distribuição granulométrica dos materiais granulares, areias e pedregulhos, foi realizado por meio do processo de peneiramento de uma amostra, enquanto, para silte e argilas se utilizou à sedimentação dos sólidos no meio líquido. Para solos, com partículas tanto na fração grossa (areia e pedregulho) quanto na fração fina (silte e argila) se torna necessária à análise granulométrica completa (peneiramento e sedimentação). As frações granulométricas foram divididas por seu diâmetro equivalente em matacões $(>20 \mathrm{~cm})$, calhaus $(20 \mathrm{~cm}$ a $20 \mathrm{~mm})$, cascalhos $(<20 \mathrm{~mm}$ a $2,0 \mathrm{~mm})$ e a terra fina $(<2,0 \mathrm{~mm})$ EMBRAPA $(2017)$

Portanto, de acordo com os procedimentos e normas de qualidade deste, o objetivo principal foi de levantar informações que auxiliem na caracterização do grau de erosão e intemperismo das coberturas superficiais e distinção das pedossequências, além de poder gerar dados com subsídio para o planejamento e gestão de obras de engenharia, sítios urbanos e atividades agrícolas.

Granulometria: as amostras foram preparadas seguindo a técnica de análise proposta pela EMBRAPA (2017) e peneiradas conforme a Escala de Wentwoeth (1922, apud SUGUIO, 1973). De acordo com os conteúdos de areia, silte e argila, foram caracterizadas as classes de textura, segundo diagrama proposto no manual de Lemos \& Santos (1986) e IBGE (2005): areia, silte, argila, areia-franca, franco, francoargiloarenosa, franco-argilosa, franco-arenosa, argiloarenosa, muito argilosa, argilossiltosa, franco-argilossiltosa e franco-siltosa. Também foram quantificadas as frações grosseiras (cascalhos grossos e finos) e matéria orgânica.

\section{RESULTADOS E DISCUSSÃO}

Logo após a realização das leituras bibliográficas, atividades de campo, coletas de dados foi possivel constatar alguns problemas ambientais. Relacionado aos problemas ambientais do Município, pode-se ressaltar alguns dos quais são bem presentes. A princípio tem-se a poluição dos recursos hídricos, que é provocada pela atuação indevida de práticas humanas como acúmulo de resíduos sólidos nas margens dos rios, escoamento de efluentes para áreas fluviais, impactos que podem gerar entre outras modificações processos de eutrofização de espécies e provocar a escassez deste recurso natural.

Por conseguinte, tem-se o assoreamento, que é ocasionado devido o desmatamento das margens dos rios acelerando a formação de bancos de areia e alargamento do canal fluvial. Outro impacto que o município enfrenta é a especulação imobiliária por mais que não afete diretamente a população, mas devido à ocupação em áreas de proteção ambiental -APA, como é o caso das áreas de morros, que modificam o ambiente e podem causar inundações e até 
deslizamentos de terras com vítimas. Além desses, tem-se os problemas relacionados aos solos como é o caso da erosão, que retira os solos de um determinado local e carrega para outras áreas.

É sabido que com a presença dos problemas ambientais as paisagens do Municipio vêm passando por transformações. Em lições de Costa Falcão (2008) pode-se apontar a ausência da vegetação que deixa o clima da região mais quente colaborando para o processo de erro são problemas ambientais tais como o desprovimento da vegetação, deixando o clima da região mais quente propiciando o processo de erosão e o desaparecimento de várias espécies responsáveis pela cobertura do solo.

No que diz respeito a amostra analisada da classe dos Argissolos Vermelho-Amarelos, a vegetação cultivada é o milho, tendo como vegetações secundarias o babaçu e o capim, a área é formada por material alterado, proveniente do granito Meruoca, como afirma Diniz (2010). A área da coleta possui alta estrutura com substrato regolitico gleico, dificultando o plantio (Figura 04 e 05).
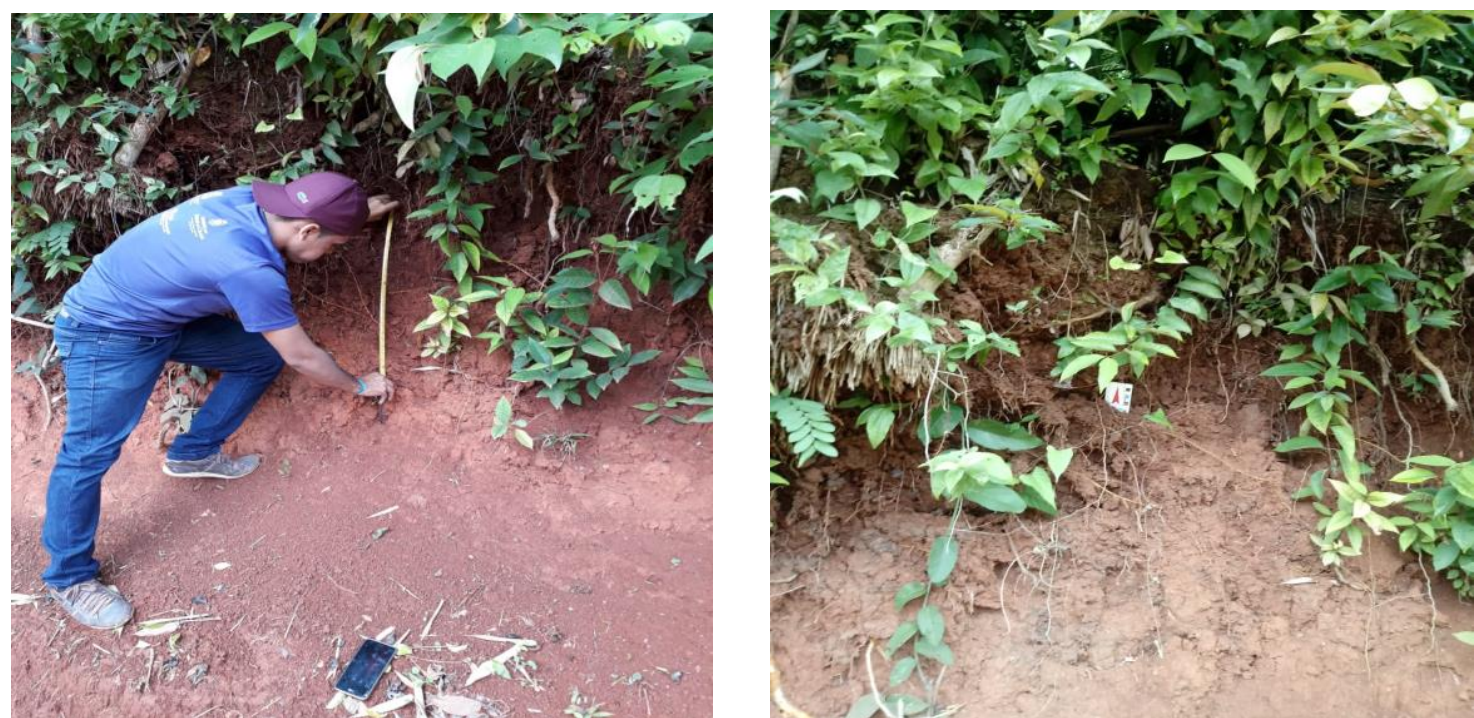

Figura 04 e 05: Coleta de solo da classe Argissolos Vermelho- Amarelos Fonte: Autores (2019)

No que se refere à análise granulométrica do Argissolos Vermelho-Amarelos, esta apresentou $60 \%$ de silte indicativo de baixo teor de coesão e pouca plasticidade. O que comprova os impactos nas estradas da serra no período chuvoso e formação de pó quando no período seco, podendo se agravar com o desmatamento.

Em relação a amostra da classe dos Neossolos a amostra analisada está localizada em uma área com vegetação de milho e babaçu. A amostra analisada apresentou grande teor de areia > que 50\%. Em relação à consistência quando molhada não plástica, friável, com concreções, presença de quartzo, alto grau de floculação, poroso, com formação litológica 
granítica. O ambiente está protegido pela vegetação, porém se a área for desmatada pode gerar um processo erosivo acentuado, com perda de solo e afloramento de rocha, fato comum nas áreas desmatadas da serra, que não fazem parte da APA. (Figura 06 e 07).
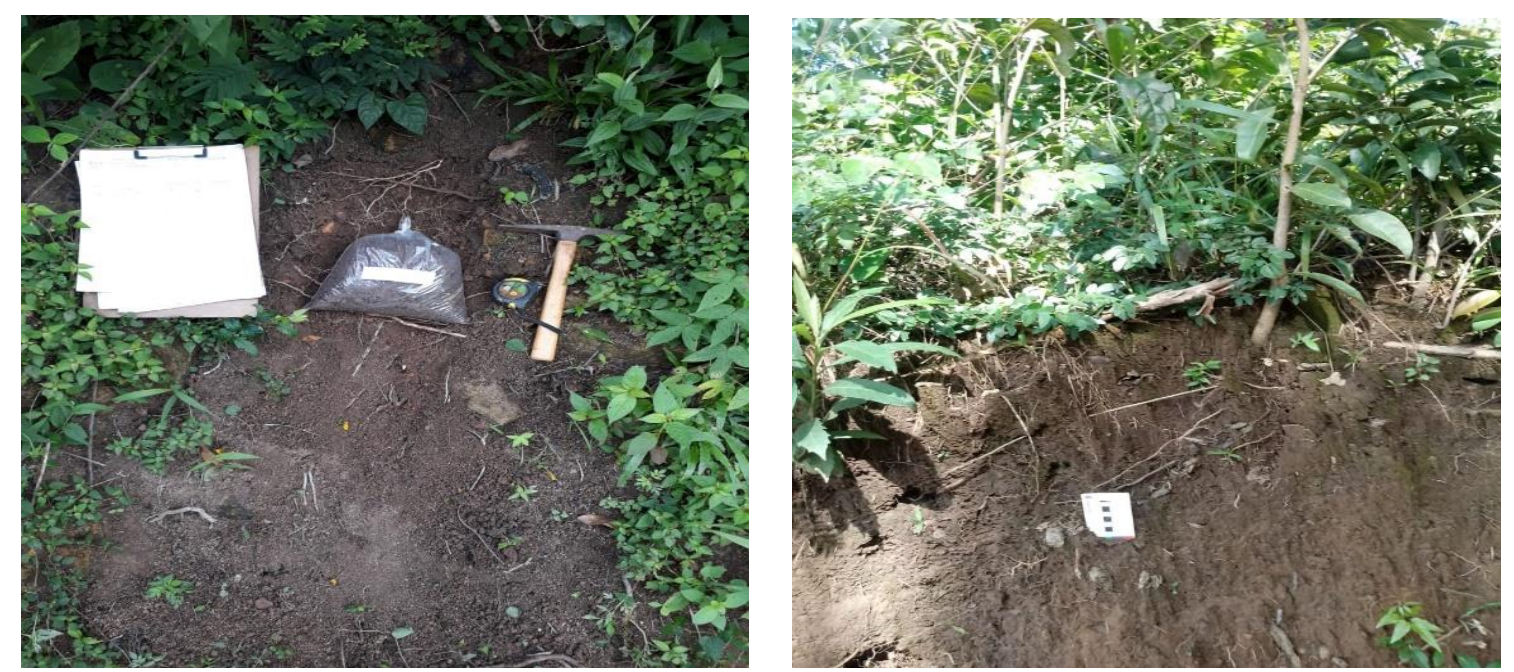

Figura 06 e 07: Coleta de solo da classe Neossolos Fonte: Autores (2019)

Em referência as análises físicas foram fundamentais, pois caracterizam a textura do solo, baseada nos teores de areia, silte e argila. É necessária para financiamento de custeio agrícola como para esta pesquisa. Mensura o adensamento e a aeração do solo através da determinação das densidades global e real, e da porosidade. Nesse contexto, dentro da análise física tem-se a análise granulométrica envolvendo a (areia, silte e argila), argila natural, grau de floculação, densidade de solo (proveta) densidade de partícula, porosidade total. Entretanto, as diversas formas inapropriadas de usos executados ao longo do tempo, causaram descaracterizações nesse ambiente, afetando assim a competência de recuperação desses ecossistemas e causando problemas socioambientais pertinentes.

\section{CONSIDERAÇÕES FINAIS}

Perante as informações alcançadas, podemos perceber que os problemas ambientais vêm se agravando distintamente no tempo-espaço onde está associado à estrutura fisionômica da paisagem, tendo em vista que a natureza é um sistema dinâmico que está interligado a todos os elementos naturais sendo elementos de uso estrutural concreto da sociedade e da cultura, decorrentes a esses problemas os solos vem passando por processo de degradação, envolvendo o desenvolvimento agrícola que sempre esteve presente no Município, motivo esse que causou transformações na paisagem local, implicando em problemas ambientais, que contribuem para a erosão dos solos. 
Sabendo que o Município pertence a uma área de proteção ambiental- APA o poder público juntamente com alguns órgãos que são responsáveis em cuidar do meio ambiente, devem propor medidas mitigadoras como ações do sistema nacional de unidades de conservação, fiscalizando e monitorando as UCs fundadas pela união, buscando amenizar esse problemas negativos não deixando com que esses problemas afetem cada vez mais o meio natural, gerando assim um desequilíbrio ambiental.

\section{REFERÊNCIAS}

AB'SÁBER, A.N. Domínio Morfoclimático Semiárido das Caatingas Brasileiras. Geomorfologia, n. 43 IG- USP. São Paulo, 1974.

AB'SÁBER, A.N. Sertões e Sertanejos: uma geografia humana sofrida. Revistas Estudos Avançados, São Paulo, v.13 n 36, p 7-59,1999

AB'SÁBER, A.N. Os domínios de natureza no Brasil: potencialidades paisagísticas. São Paulo, SP: Ateliê Editorial, 2003.

BERTALANFFY, L. Teoria geral dos sistemas. 3 ed. Petrópolis: Vozes, 2008

BRASIL. Ministério do Meio Ambiente. Quinto Relatório Nacional para a Convenção da Biodiversidade. $\quad$ Brasília: MMA, 2016. Disponível em:< http://www.mma.gov.br/informma/item/10772-quinto-relat\%C3\%B3rio>. Acesso em $01 / 08 / 2019$

COSTA FAlCÃO, C. L. Avaliação Preliminar dos Efeitos da Erosão e de Sistemas de Manejo na Produtividade de um Argissolo na Serra da Meruoca. Dissertação de Mestrado - UFC, Fortaleza, 2002.

COSTA FALCÃO, C.L. A dinâmica erosiva do escoamento pluvial em área de depressão sertaneja e de maciço residual no semiárido cearense. 2008. Tese (Doutorado) - Curso de Geografia, Universidade de São Paulo- USP, São Paulo, p.1-254, 2008.

COMPANHIA DE PESQUISA DE RECURSOS MINERAIS (CPRM) Atlas dos Recursos Hídricos Subterrâneos do Ceará: Programa Recenseamento de Fontes de Abastecimento por Água Subterrânea no Estado do Ceará. Fortaleza: REFO, 1998

COMPANHIA DE PESQUISA DE RECURSOS MINERAIS (CPRM) Serviço Geológico do Brasil. Ministério de Minas de Energia. Mapa Geológico do Ceará, 1:100.000 CPRM, 2014

CONAMA. Conselho Nacional do Meio Ambiente (Brasil). Resolução no 001/ de 23/01/ 1996 Disponível em:<http://www.mma.gob.br>. Acesso em: 18 set. 2018

CHRISTOFOLETTI, A. A geografia física no estudo das mudanças ambientais. In: CHRISTOFOLETTI, A. et al. (Org.) Geografia e meio ambiente no Brasil. São Paulo: Hucitec, 1995. p.334-45 
DIAS, R. Gestão Ambiental: Responsabilidade Social e Sustentabilidade. São Paulo: Atlas, 2008.

DINIZ, S. F. Caracterização fisiográfica e pedológica da Região Norte do Estado do Ceará. (Tese de doutorado). Universidade Estadual Paulista, Rio Claro, 2010.

EMBRAPA. Manual de métodos de análise de solo / Paulo César Teixeira ... [et al.], editores técnicos. - 3. ed. rev. e ampl. - Brasília, DF: Embrapa, 2017.

FALCÃO SOBRINHO, J; COSTA FALCÃO, C. L. Práticas agrícolas inadequadas acentuam processos erosivos na serra da Meruoca. Ver. Ci. e Téc., Fortaleza, ano 3, n.3.p.25-26, dez/2001

FONTANA, A. Preparo de Amostras e Separação de Terra Fina, Cascalho e Calhaus. In: EMBRAPA. Manual de métodos de análise de solo / Paulo César Teixeira ... [et al.], editores técnicos. - 3. ed. rev. e ampl. - Brasília, DF: Embrapa, 2017.

INSTITUTO BRASILEIRO DE GEOGRAFIA E ESTATÍSTICA (IBGE). Manual técnico de pedologia. Rio de Janeiro: IBGE, [2005]. 300 p.

LEMOS R.C. \& SANTOS, R.D. Manual de descrição e coleta de solos no campo. 3.ed. Campinas, Sociedade Brasileira de Ciência do Solo, 1986. 85p

SOUZA, M.J.N. Contribuição ao Estudo das Unidades Morfoestruturais do Estado do Ceará. Rev. de Geologia v.1, ed. UFC. Fortaleza, p.73-91. 1988.

SOUZA, M.J.N. OLIVEIRA, V.P. V. Os enclaves úmidos e sub-úmidos do semi-árido do nordeste brasileiro. Mercator - Revista de Geografia da UFC, ano 05, número 09, 2006.

SUGUIO, K. 1973. Introdução à Sedimentologia. USP, São Paulo, 316 pp.

\section{AGRADECIMENTOS}

À FUNCAP pela concessão da bolsa para a realização da pesquisa e ao Mestrado Acadêmico em Geografia da Universidade Estadual Vale do Acaraú- CEMAG/UVA.

Recebido em: 14/08/2019

Aceito para publicação em: 01/11/2019 